\title{
Demystifying Tree Forks: Vices and Virtues of Forks in Arboriculture
}

\author{
Christophe Drénou ${ }^{1}$, David Restrepo ${ }^{2}$ and Duncan Slater ${ }^{3 *}$ \\ ${ }^{1}$ Centre National de la Propriété Forestière (CNPF), Institut pour le développement forestier (IDF), France \\ ${ }^{2}$ Service de l'arbre et des bois de la Ville de Paris, France \\ ${ }^{3}$ Greenspace department, Myerscough College, England
}

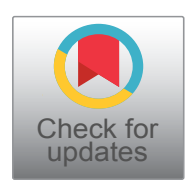

\begin{abstract}
Concluding that all tree forks are structural defects and that they are inherently weak regardless of their specific nature, reveals a profound lack of understanding of tree development. How many tree forks are considered a hazard within a tree's structure when they are not? It is only in recent times that interdisciplinary approaches comprising tree architecture, biomechanics and mechanobiology have been considered in arboriculture to embrace a new perspective on this topic. In the present article, we seek to demystify false conclusions lacking scientific rigour on tree forks. We go in depth into the anatomical and architectural nature of this morphological structure according to endogenous or exogenous factors, how it is formed and its function in most broadleaved trees and certain conifers.
\end{abstract}

\section{Issues and Challenges}

In a tree, a fork is a morphological structure produced by the bifurcation of an axis yielding two or more equivalent axes, roughly of the same diameter.

For quite some time, tree forks have been regarded in many arboricultural texts as structural defects. For instance, the popular tree risk assessment guide by Matheny and Clark, 1994 , states that " [b]y definition, codominant stems are a structural defect" (p.9) [1]. This notion comes straight out of the forestry industry. In commercial wood production, the aim of the forester is to exploit the trunk as high as is viable, obtaining as much straight-grained wood as possible. This is best achieved by the regular pruning and removal of lateral branches, before their insertion cone becomes too thick, making a knot that may compromise the strength and solidity of the wood being produced. Where the tree trunk bifurcates, the forester's aim is abruptly stopped because the trunk cannot be exploited any higher for good quality timber. For this reason, foresters regard all forks as structural defects in terms of timber production. Unfortunately, this notion has been adopted into arboricultural training; however, there is no logical reason for this since our aim in arboriculture is not to produce timber commercially but to establish trees in an urban context.

Parallel to this, all tree forks are regarded in many arboricultural texts as inherently weak structures, regardless of their specific nature. The afore-mentioned guide states that "[c]odominant stems are inherently weak because the stems are of similar diameter" [1]. Considering a fork as inherently weak, justified only based on axes ratio is not founded on persuasive or extensive scientific study.

When we look at a mature tree developing through a strategy of reiteration that has established a strong, solid and stable main fork as a result of a long and progressive architectural metamorphosis, we are witnessing that all forks are not weak structures. Certain forks, especially main forks, are so strong, solid and stable that they may be the most reliable structure formed in the tree, capable of supporting the entire broad-crown and its wind-induced oscillations.

\section{Terminological Approach to Tree Forks}

The botanical term for a junction yielding two or more equivalent axes that form sharp angles between them is ' $a$ fork'. However, forks have also been referred to as 'codominant stems' in arboriculture since the early 1970s, a term that is strongly established. The term 'co-dominant stems' can be traced, in forestry literature, all the way back to the 19th century, originating in the English translations of the crown classification system by Gustav Kraft, which was published in Ger-

*Corresponding author: Duncan Slater, Greenspace department, Myerscough College, Preston, Lancashire, England

Accepted: September 26, 2020

Published online: September 28, 2020

Citation: Drénou C, Restrepo D, Slater D (2020) Demystifying Tree Forks: Vices and Virtues of Forks in Arboriculture. J Bot Res 3(1):100-113 
man in 1884. Kraft's classification system is based on a tree's social status in a forest stand, considering its height, crown extent, symmetry and vitality. According to Kraft, trees in a stand are distinguished as being predominant, dominant, and co-dominant. One of the main books to introduce Kraft's classification system was "The Principles of Forest Yield Study", written by Ernst Assmann and translated from German into English in 1970. In this book the term 'dominant stems' was used to refer to dominant trees in a forest stand. In "Trees Structure and Function", written by Martin H. Zimmermann and Claud L. Brown in 1971, the term 'co-dominant', referring to a fork, appears, if only once; this single reference happens to be associated with pruning in an illustration, thus causing a major influence upon modern arboricultural literature [2-4].

This is the relevant excerpt from Zimmermann \& Brown, 1971: "Two co-dominant lateral branches growing upward at acute angles tend to exert a mutual epinastic effect on each other. If either is removed by pruning, the remaining leader will assume the vertical position", p.138. For Brown, the 'mutual epinastic effect' is the dominance exerted on lateral branches by the apex. In this context, the term implies competition for apical dominance. The term 'co-dominant stems' implies a condition, it describes a situation occurring above the fork, not the fork itself. It implies that apical dominance is being disputed between axes.

The term 'codominant stems' at this stage is not about the fork as a structure but refers to a condition between stems. This structure, where a tree bifurcates, dividing the stem into two or more roughly equal elements is more appropriately called 'a fork', not 'co-dominant stems'. The latter term generalizes, taking for granted that all elements of a fork "exert a mutual epinastic effect on each other", as described by Brown in 1971. However, not all forks are constituted of arising axes that dispute this apical dominance. All forks are not equal. In tree architecture research, forks are classified into four different types that are physiologically and morphologically distinct. In fact, only one type of fork may be considered as having co-dominant equivalent axes disputing the apical dominance: i.e. accidental forks (discussed further below) [4].

\section{Anatomical Approach to Tree Forks}

So how did arborists come to consider all forks as inherently weak structures, regardless of their specific nature?

The notion of the 'weakness' of a tree fork was very likely extrapolated from the concept of 'weak apical dominance' [5-8] referring to the 'decurrent' polyarchic nature of forks. Although the terms 'weak apical dominance' and its analogous term, 'strong apical dominance' have nothing to do with structural strength, solidity and stability, these 'growth habits' are reflected in many arboriculture texts associated respectively with weak and strong attachments, further reinforced by the claim that they lack overlapping collars, a hypothesis by Alex Shigo that has been dismantled by recent research in contemporary arboriculture [9].

The ISA arborist certification guide [10] defines forks as follows: "Codominant stems: forked stems nearly the same size in diameter, arising from a common junction and lacking a normal branch union" [10]. The phrase "lacking a normal branch union" implies abnormality. This relates to the legacy that Shigo's 1985 article left to arboriculture when he presented "How tree branches are attached to trunks" [11]. This reference article overlooks forks as a morphological structure and the mechanical properties of the specialized wood (axillary wood) that lies under the bark ridge, introducing the notion of a strong attachment based on the hypothesis of overlapping collars. Shigo's hypothesis claims that the branch makes its annual rings during the spring and the trunk during the summer, thus overlapping collars are formed. This asynchronous cambial activity was considered typical of diffuse-porous trees $[8,12]$. However, there are numerous inconsistencies with Shigo's hypothesis. The most evident inconsistency is the fact that cambial activity occurs simultaneously in ring-porous species $[8,12]$.

Shigo's hypothesis has rarely been tested scientifically, apart from Dan Neely's research in the 1990s and Duncan Slater's research from 2010 onwards [13-15]. Neely undertook a series of experiments in the early 1990s injecting different species of trees with a water-soluble dye, methyl violet, at the branch-to-stem junction. He traced the pattern of translocation and concluded that "if Shigo were correct, the dye injected late in the season would remain in the stem" [13]. A quarter of a century onwards new research sheds new light on Shigo's hypothesis, forcing the arboriculture community to wake up and realize the lack of scientific research regarding branch junctions. This research is yielding immense reforms to the way we understand tree forks. If the old branch attachment model was correct, the wood grain direction would change orientation within each annual ring at the point of attachment: the branch grows a collar, then the trunk grows a collar, in this old model, so the grain orientation must change within an annual ring for that model to be applicable. We can confirm never seeing that year on year consistent 'flipping' of the wood grain orientation at a branch junction, and samples that were X-rayed at The University of Manchester failed to find these overlapping collars too [9].

There are also other challenges persisting with Shigo's hypothesis. If overlapping collars in the junction are caused by sequential growth, why are bark inclusions typically formed as a continuous sheet at the top of the branch junction? When a branch junction is split from below, why does the wood grain pattern go straight from the stem into the base of the branch? (i.e. no sign of any 'trunk collars'). The most common failure mode of a branch junction is for it to split at its apex under tension or due to a mix of tension and torsion. With the collar-upon-collar model, it does not appear that the apex of the junction is mechanically reinforced any more than the sides, which is illogical. What tissues take the most critical loading at the apex of the branch junction? The hypothetical development of overlapping collars does not explain the dense tissues consistently found under the bark ridge formed at most branch junctions.

Recent research reveals an important biomechanical attribute of junctions in trees by introducing the concept of a complex and tortuous interlocking wood grain at their core, referred to as 'axillary wood', that resists the junction being 


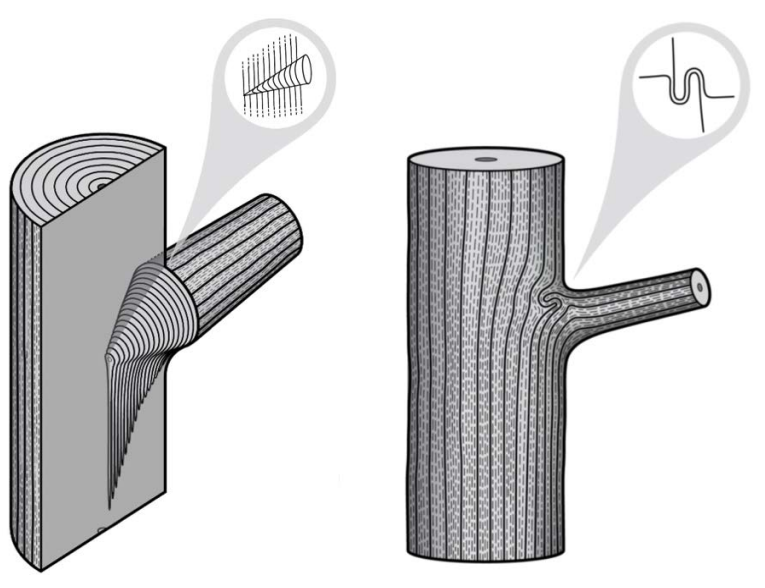

Figure 1: (left) Schematic diagram of the attachment of a branch to the trunk of a tree with a classical insertion cone; (right) schematic diagram of the interlocking wood grain of a branch attachment in a tree; both based upon the anatomical model of Slater, et al. [10]. Illustration courtesy of Duncan Slater [47].

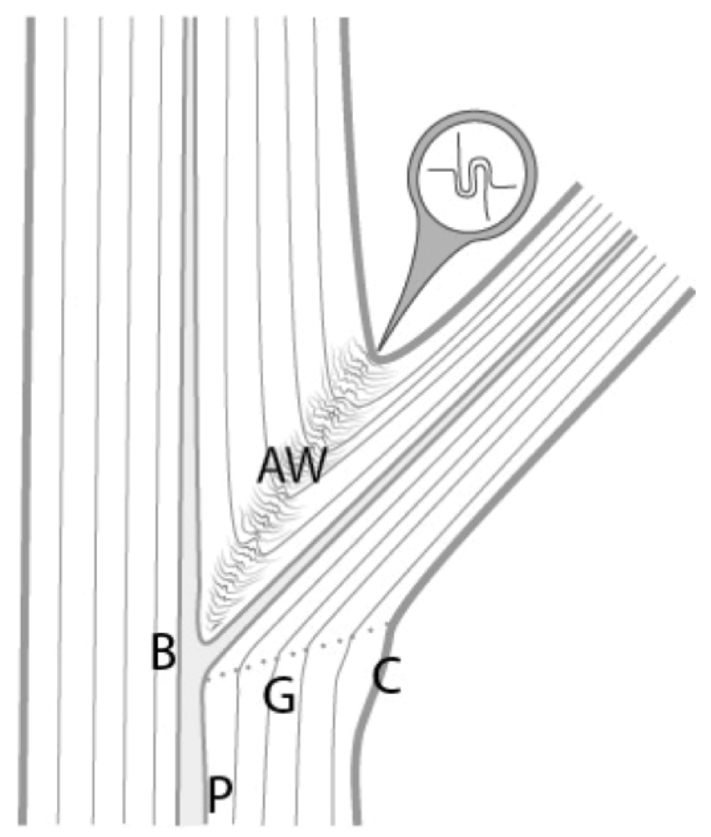

Figure 2: Key anatomical features providing mechanical support to a branch-to-stem junction. $P=$ pith; $B=$ bifurcation of the pitch; $A W=$ axillary wood; $C=$ branch collar; $G=$ "grain capture zone" where the wood grain pattern either enters the base of the branch or diverts around the branch to supply the stem set above the branch attachment [52].

pulled apart $[9,15]$. Axillary wood is a type of reaction wood formed under the junction's bark ridge, induced by mechanical stimuli (thigmomorphogenesis). This research highlights the anatomical similarities of a spectrum of junctions in trees and how their anatomy varies with their etiology and aspect ratio (Figure 1, Figure 2, Figure 3, Figure 4 and Figure 5). A key facet of most junctions in trees is a dense wood exhibiting interlocking grain patterns formed under the junction's bark ridge, which typically consists of much denser wood and is typically more developed when the two joined axes are roughly of equal diameter.

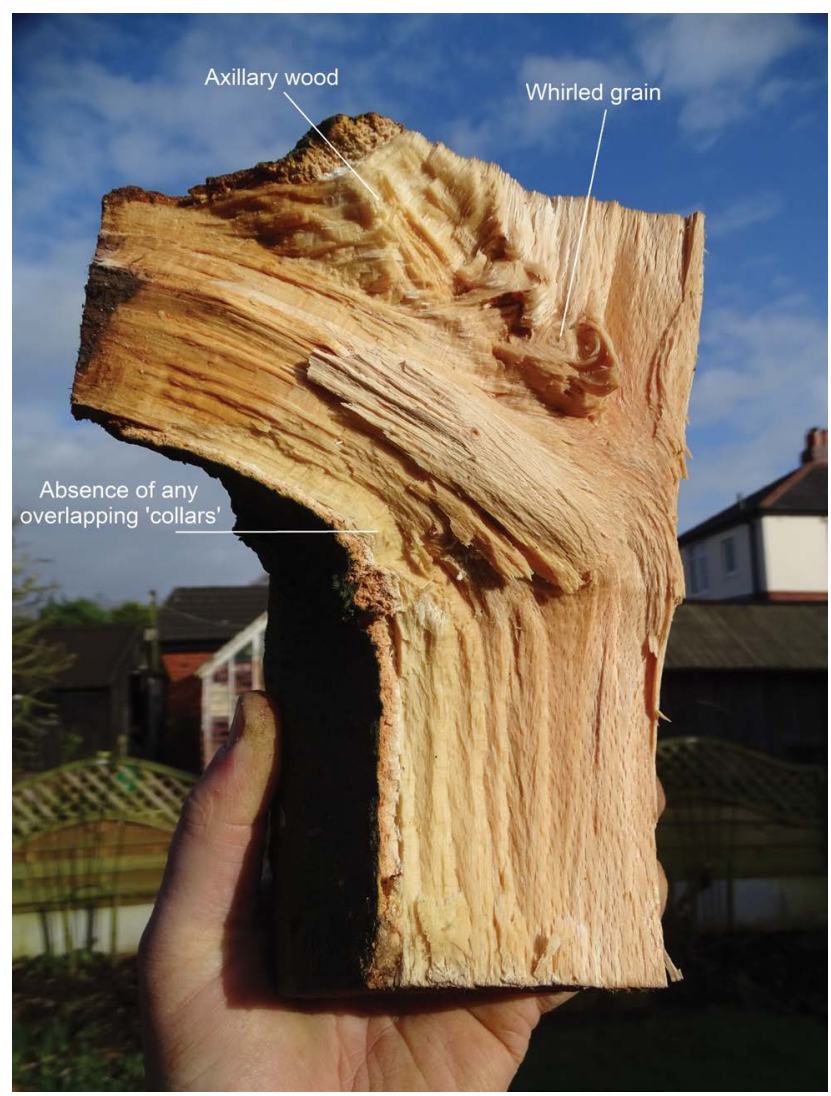

Figure 3: Axillary wood exhibited in a split branch junction in common beech (Fagus sylvatica L.)

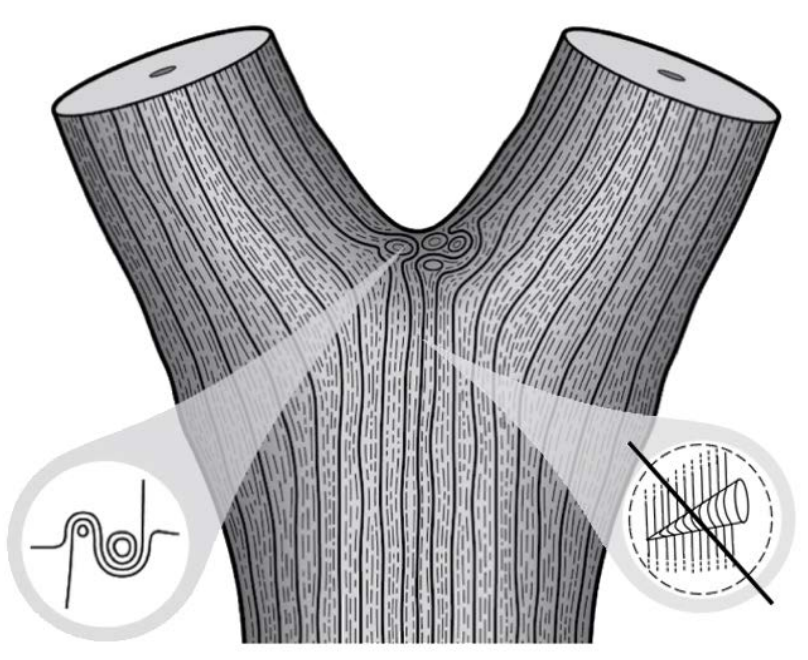

Figure 4: Schematic diagram of the dense interlocking wood grain in a main fork, based upon the anatomical model of Slater, et al. [8], with inset (far left) displaying a basic interlocking pattern of wood grain incorporating whirled grain in the $x-y$ plane, and, inset (far right) displaying the lack of a classical insertion cone.

\section{Architectural Approach to Tree Forks}

What is the function of forks in a tree? If we approach the nature of forks by considering their function, we find four distinct architectural situations [16-18]: 1) Main forks are responsible for the crown's construction in trees developing through a strategy of reiteration; 2) In certain species, 
recurrent forks provide great architectural plasticity to young trees in order to adapt to environmental vicissitudes; 3) When growing conditions are unfavorable, especially when light is insufficient, standby forks make it possible to increase the photosynthetic area; and 4) Finally, accidental forks substitute, supplying traumatized axes. These forks can be endogenous and genetically inherent (main forks and recurrent forks) or induced by exogenous factors (accidental forks and standby forks). They may have a permanent character (main forks and many accidental forks) or a transitory nature (recurrent forks and standby forks with respect to environmental fluctuations).

\section{Main Forks}

It is necessary to make a clear distinction between a fork on a young tree, where natural pruning has barely begun, and a strong, solid and stable first main fork that is meant to bear the main structural branches of an adult tree. This first main fork marks the end of the trunk's construction. The

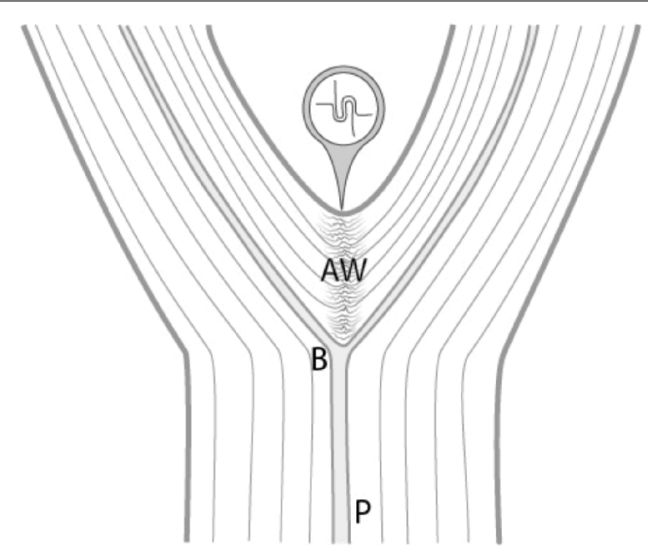

Figure 5: Key anatomical features providing mechanical support to a main fork. $\mathrm{P}=$ pith; $\mathrm{B}=$ bifurcation of the pith; $\mathrm{AW}=$ axillary wood. emergence of a main fork is the result of a slow and progressive architectural metamorphosis ${ }^{(i)}$ [19-21]. While a young tree is growing in height, the succeeding uppermost branches become more and more upright and wind up acquiring a trunk morphology (phenomenon of reiteration by dedifferentiation), thereupon, a first fork is formed (Figure 6). In Populus spp., a tree with monopodial(ii) growth, the uppermost branches wind up relaying the trunk after the death of the shoot apex. Prunus avium, also with monopodial growth, establishes a main fork; however, without prior death of the shoot apex; the trunk continues its growth after the emergence of the main structural branches. In Juglans regia, in the absence of trauma, usually a main fork is established after terminal flowering of the trunk [22].

The emergence of the first main fork is associated with the transition of a development stage, i.e. the passage from the young stage (architectural unit) to the adult stage (reiterative phase in trees developing through a strategy of reiteration). It is usually preceded by numerous forks developing on side branches. These lateral forks emerge closer and closer to the trunk, from low branches towards the top of the tree, and wind up foretelling the main fork emerging directly on the trunk. Thus, in the field, the observation of branches is a means of identifying a tree's first main fork ahead of its development. The height of the latter varies considerably depending mainly on light exposure (in bright light, a main fork emerges very close to the ground); competition between trees (higher fork in a dense woodland environment), and species (pioneer species, such as Alnus spp., Betula spp. and Populus spp. may establish a high fork even in an open environment). In cities, parks or along roads, trees often exhibit a

(i) Architectural metamorphosis refers to a progressive change in functioning of apical meristems.

(ii) Monopodial refers to the growth of an axis ensured by the single terminal bud. The terminal bud governs the elongation of the axis.

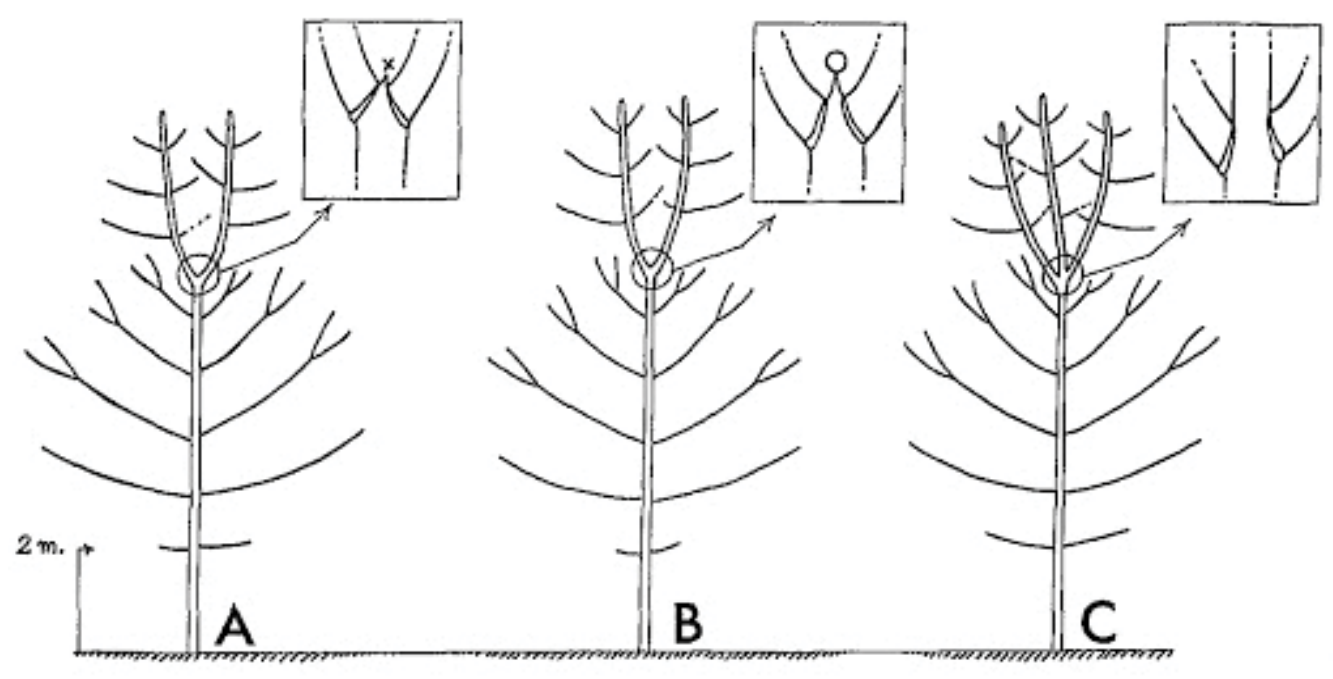

Figure 6: The emergence of a main fork is the result of a slow and progressive architectural metamorphosis. Note the lateral forks on side branches that emerge closer and closer to the trunk until the formation of a main fork. When the latter is put in place, the trunk undergoes death of its apex, as in Populus nigra (A); the apex transforms into a flower, as in Juglans regia (B); or the apex loses its apical dominance, as in Prunus avium (C). 
long trunk even though they grow in an open environment. This forest tree aspect is artificial, as a result of the frequent removal of low branches from an early age to leave a passage high enough for vehicles. This simulated dense woodland effect, through pruning, often forces trees to establish a much higher first main fork.

The crown of a broadleaved tree developing through a strategy of reiteration exhibits a series of main forks along its main structural branches. These are the result of successive reiterations of the initial architectural unit (the young tree). Every main fork marks the passage from one reiteration to the next in successive waves that account for markers of development. Without reiteration, the crown of the tree is not yet formed, the tree remains young. Annual growth in height increases throughout the youth phase and reaches (in a forest) a maximum elongation just before the formation of the first main fork. From 1 to 4 successive waves of reiterations, main structural branches explore the space, the tree is adult. During the adult phase, annual growth in height decreases while the annual growth in cross-sectional area increases. From 5 to 10 successive waves of reiterations, the crown reaches its maximum extension, the tree is mature. Annual growth in cross-sectional area is then maximal as well as the leaf area. Beyond 10, the tree enters its senescence stage. Surprisingly, these thresholds vary little from one species to another [23,24].

Main forks also occur in conifers, in species building their crowns by reiteration (including but not limited to Ginkgo biloba, Pinus halepensis, Pinus pinea \& Taxus baccata). Other species, developing by gigantism (i.e. without reiteration of the initial architectural unit) do not form main forks (including but not limited to Araucaria spp., Picea spp., Pseudotsuga spp. \& Sequoia sempervirens). Certain conifers which adopt a strategy of gigantism, achieving their phase of elongation, modify their architecture. Some produce a few closely spaced series of forks at their top (including but not limited to Abies spp.) [25]; others form a 'table' by terminal drooping of the trunk (including but not limited to Pinus nigra v. Iaricio, P. sylvestris \& $P$. uncinata).

\section{Recurrent Forks}

Some species are constructed entirely of drooped plagiotropic axes (with a horizontal growth orientation and bilateral symmetry) of which only the basal part is more or less upright. Each drooped module is inserted in the curved area of the previous one and forms a recurrent fork with it. Only the upright base of the axis is perennial and participates in trunk formation, while the horizontal part takes the role of a branch. This mode of development is characteristic of Troll's architectural model. It seems to be the most frequent in both tropical and temperate woody species, quite prevalent in the Fabaceae (Leguminosae) family (including but not limited to, Cercis siliquastrum, Gleditsia triacanthos, Robinia pseudoacacia) [26]. Also, in the Ulmaceae family (including but not limited to, Celtis spp., Ulmus spp., Zelkova serrata), the trunk formation is characterized by the recurrence of forks superposed on each other (Figure 7).

In some species not belonging to Troll's architectural model (including but not limited to, Quercus robur, Quercus petraea, Quercus pubescens), the trunk is also constructed via a series of endogenous recurrent forks. As a result of the combined effect of sympodial ${ }^{(i i)}$ growth and weak apical dominance: the abortion of the terminal bud is annual and each time, several oblique lateral axes develop forming a recurrent

\footnotetext{
(iii)Sympodial growth on an axis implies abortion or transformation of the apex (into a flower, tendril, thorn, etc.) and a relay of growth by one or more axillary buds.
}

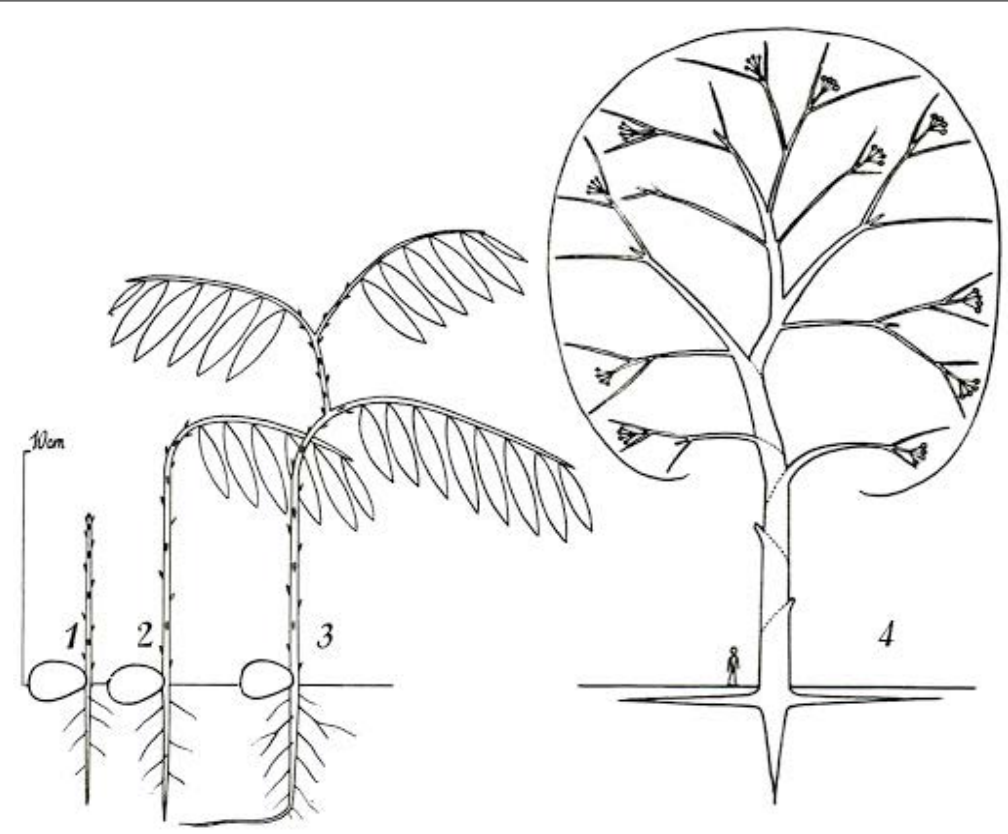

Figure 7: Recurrent forks as a result of superposed drooped plagiotropic axes. 1. Germination; 2. First plagiotropic differentiation; 3. Successive superposed modules; 4. Adult tree (Parinari excelsa Sabine). Troll's architectural model - Illustration taken from Hallé and Oldeman, [53,54]. 
fork where the arising axes explore the space. These recurrent forks are most often resorbed within two to three years after their emergence. One of the arising axes acquires dominance over the other(s), straightens itself up and relays the construction of the trunk.

Recurrent forks give great architectural plasticity to young trees that can, according to the experienced perturbations, deform in their quest for light, bypass an obstacle, partially sacrifice an axis and undergo a relay underneath. The recurrence of forks, as they are resorbed over time, yields an initially tortuous trunk that may become, in many cases, perfectly straight as it increases in girth.

\section{Standby Forks}

In a forest environment, it is not unusual to encounter forked young trees (height more or less inferior to 6 metres), taking on a bushy appearance or forming a 'table'. Such trees usually grow in unfavorable light conditions, especially in dense woodlands, and 'wait' for their environment to improve.

For instance, in Castanea sativa, in an optimal environment, the axis arising out of the seed builds from the outset a trunk with branches that are clearly differentiated. On the other hand, when light levels are low, the young tree forms a series of drooped forks without apical dominance. It remains on standby awaiting to regain enough vitality, and resorts to its latent buds, or, less frequently, its annual shoots and then resumes its development. Sometimes, when light resources are insufficient, the new shoots established 'fall back' after a few years, into a secondary system of standby forks. Some specimens may become hopelessly 'stuck' in such a loop.

When light is too weak, Fagus sylvatica also develops in a peculiar way. The tree is thin, upright, bearing practically no branches and it exhibits a small flat crown, as a result of the drooped terminal part of the trunk and the last lateral axis formed. As with Castanea sativa, this standby fork may be resorbed in Fagus sylvatica if light resources improve, passing from a dense forest to a thinned forest, for example [16].
Neither of the preceding examples are isolated cases. Many species, including but not limited to, Quercus ilex, Quercus petraea, Quercus robur and even conifers, such as Cedrus spp. and Pinus spp. may produce standby forks [27].

\section{Accidental Forks}

During the development of a tree, many factors may damage the tip of the leader, such as rodents, deer, birds, insects, climatic perturbations (frost, wind, drought) and other factors. The tree tries to restore the missing part, but this regeneration is not always immediate and flawless. Two types of reaction may be observed: the straightening up of side branches near the damaged tip of the leader, or the formation, from latent buds, of one or more new axes with a vertical orientation of growth. In both cases, the trunk will show a 'bayonet-shaped' deviation if a single relay is established, or a fork if two axes acquire an equivalent development.

The resorption of an accidental fork by one of the shoots, straightening up and becoming dominant, depends on several factors.

\section{The Extent of the Accident}

On a vigorous young tree, for example, the higher the proportion of trauma, the stronger the reaction, therefore the greater the number of epicormic shoots and the greater the probability of greater longevity for an accidental fork.

\section{Stage of Development and Physiological State}

When a trauma occurs in an ancient tree, often three or four axes will relay the continuation of the trunk; however, none of them may succeed in dominating the others. This frequently occurs with Cedrus spp., Pinus nigra v. laricio, Pinus pinaster and Pseudotsuga menziesii. Likewise, accidental forks formed on decaying trees will tend to become perennial [28-30].

\section{Tree Architecture}

The strictly monopodial functioning of some species ex-

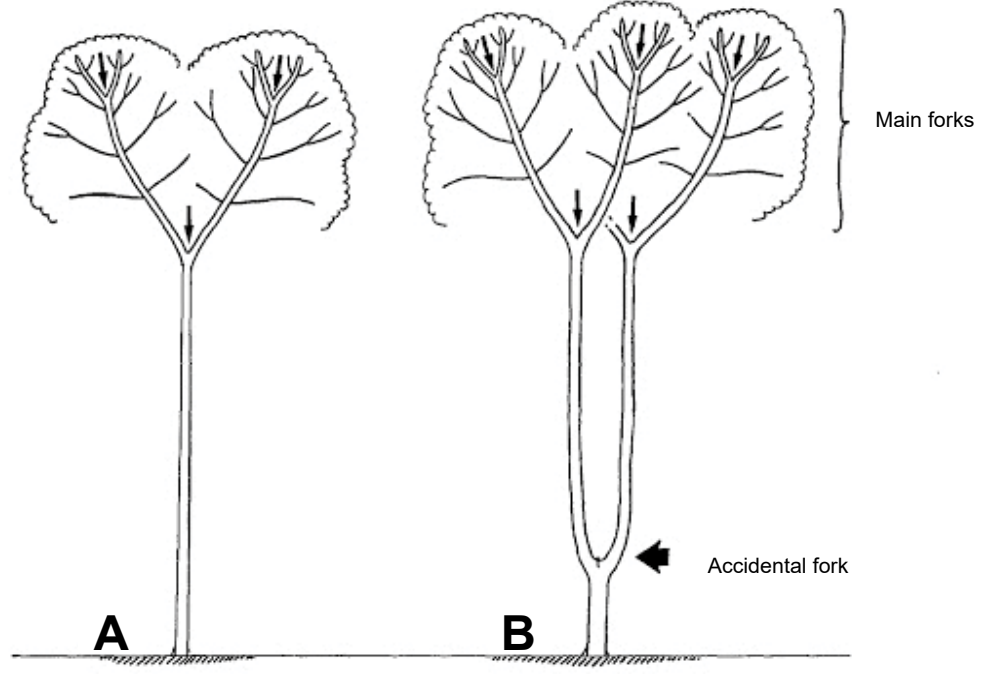

Figure 8: Contrary to the tree on the left $(A)$, the tree on the right $(B)$ formed a perennial accidental fork prior to experiencing architectural metamorphosis. 
plains in part their difficulty in resorbing forks that result from accidents occurring on the leading shoot. With species such as Fraxinus excelsior and Prunus avium, certain accidental forks may be resorbed but often others will remain [31,32].

\section{Species}

In trees with opposite buds (e.g. Acer spp., Aesculus spp, Fraxinus spp.), the trunk relays induced by accidents typically emerge in pairs, forming forks that are hard to resorb (Figure 8).

\section{Biomechanical Approach to Bark-Included Forks}

Out of the afore-mentioned types of forks, accidental forks are more likely to develop included-bark, making them susceptible to failure. This is well-known among practitioners and bark-inclusions are considered to be mechanically weak and thus undesirable to develop in the structure of an amenity tree. However, this should not be taken as a rule, since in many cases bark-included forks may compensate for their initial lack of axillary wood by reinforcing the junction with bulges. Some species are more prone than others in producing bark-included forks: e.g. Fagus sylvatica, Populus spp., Robinia pseudoacacia, Salix spp. Tilia tomentosa. Yet these species manage to form large, strong trees despite such a tendency. After all, could certain bark-included forks be as weak as we tend to think?

Bark-included forks are often formed due to a lack of ade- quate dynamic and static loading. Slater [33] emphasizes the fundamental role that mechanosensing and thigmomorphogenesis play in reinforcing junctions formed in trees. The term 'thigmomorphogenesis' was coined by Jaffe in [34], derived from the Greek word 'thigmo', meaning touch, referring to the response of plants to mechanical stimuli.

Research on mechanosensing and thigmomorphogenesis in both biomechanics and mechanobiology [35] may seem novel in arboriculture, yet over 200 years ago, in 1801, Knight undertook a series of experiments staking young trees, opening an extensive and fascinating field of observation [36]. The first observations regarding the detrimental lack of reaction wood on trees due to staking were reported by Knight: "The staking or staying with guy wires of a tree stem can prevent wind induced sway and eliminate the thigmomorphogenetic response in the trunk" ([37], referring to Knight's research).

Knight's observations were succeeded during the following centuries by a plethora of experiments in mechanoperception research, artificially exercising axes, inducing thigmomorphogenetic reactions in plants. Further observations on wind-induced thigmomorphogenesis were outlined by Metzger in 1893, whose mathematical interpretations evolved into the presently highly debated 'axiom of uniform stress' [38-43]. Prior to Knight and Metzger, over 300 years before our common era, Theophrastus 'the father of botany' had already identified thigmomorphogenesis. He observed that trees subjected to steady winds exhibited stunted growth, while trees growing in windless environments grew taller $[37,44]$. Today,

Table 1: The association between natural braces and the development of bark-included junctions in trees. Data analysis from a survey of broadleaved trees by [43].

\begin{tabular}{|l|l|l|}
\hline & Forks without included bark & Forks with included bark \\
\hline With natural braces & $15(5 \%)$ & $232(70 \%)$ \\
\hline Without natural braces & $274(95 \%)$ & $100(30 \%)$ \\
\hline Total & 289 & 332 \\
\hline
\end{tabular}

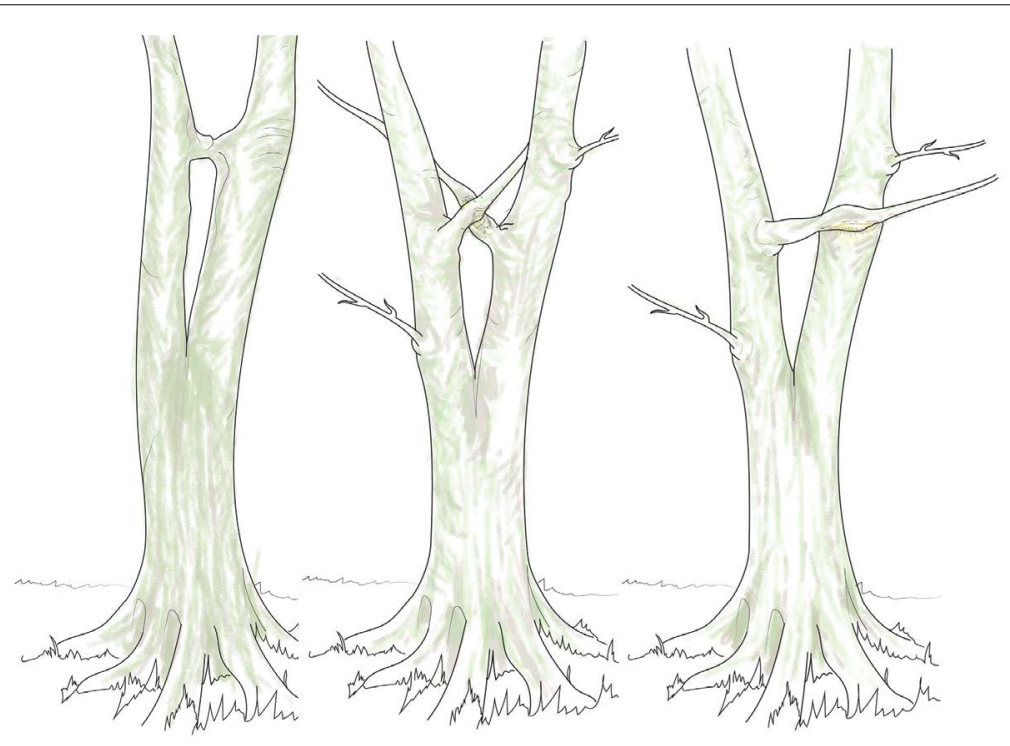

Figure 9: Three common types of natural braces responsible for the formation of bark-included forks. A. Fused branches and stems (anastomosis); B. Crossing branches; C. Rubbing branch on stem. 
we know that even fine branchlets and twigs play a crucial role in dampening wind-induced oscillations, dissipating wind energy and leading to significant mechanosensory stimuli, triggering the necessary thigmomorphogenetic response in order to reinforce branch junctions [45].

According to recent research, bark inclusions are often not originated from their conception, they are induced by a lack of oscillation and mechanical loading to the junction leading to a lack of thigmomorphogenetic response [46]. This situation occurs when elements of a junction are constrained by natural braces of different forms (Table 1 ).

There are currently ten different types of natural braces recognized as forming in trees, responsible for the formation of bark-included forks and branch junctions:

1. Fused branches and stems (anastomosis); 2. Entwining stems; 3. Entwining branches; 4. Crossing branches; 5. Rubbing branch on stem; 6 . Intermeshing twigs; 7 . Resting stems or branches; 8 . Woody climbers as natural braces; 9. Complex bracing (with adjacent objects or trees); 10. Aerial roots $[33,47]$.

Figure 9 illustrates three example types of natural brace set above a bark inclusion.

In an ongoing experiment at Myerscough College, UK, we have been able to make bark inclusions in young Populus tremula by using horticultural wire, bracing dozens of branch junctions, proving that such static bracing can cause bark inclusions to form (Figure 10).

This new research demonstrates that in the case of loss of a natural brace, a thigmomorphogenetic response leads to the formation of bulges at the base of the seam of included bark, reinforcing the junction if it does not fail (Figure 11). Initially it may be vulnerable, prone to failure, but as these bulges grow, strength, solidity and stability in the junction typically increases. This finding very much goes against the old 'rule', that if a bark-included junction has 'big ears' or has bulged substantially, then it must be in a dangerous state. Rather, when examined, these bulges are formed of dense interlocking wood grain and can be considered compensatory growth, or a form of 'repair' formed around a weakened bark-included fork. How many tens of thousands of trees have been felled because of this old 'rule' that big bulges at tree forks are bad, when there was no scientific evidence that they presented a heightened risk? The Visual Tree Assessment (VTA) methodology originated by Mattheck and Breloer [48] specifies that pointed sharp bulges, referred to as 'big ears', make the junction weaker while rounded bulges, referred to as 'small ears', are safer, but nonetheless all bulges are considered to be a weakening factor, implying a transverse crack, significantly more pronounced in 'big eared' bulges. Another common error with interpreting these cross-sections is to ignore the fact that a tree fork is a 3D structure and the apex of the fork rises over time due to secondary thickening. The wood enclosing the bark inclusion comes from bulging that occurs at the base of the bark inclusion and thickens both upwards and outwards - not just outwards.

Furthermore, the 'compression fork' model applied to bark-included forks, as proposed by Mattheck [39,41,49,50], where incremented secondary growth on the arising axes exerts pressure against each other, does not match up with the more recent findings on natural bracing. There is no such incremental internal growth where the bark-on-bark contact occurs. Instead, further secondary thickening occurs around the bark inclusion, not by the stems endlessly pushing against each other, either side of the included bark (Figure 12).

\section{Synthesis}

The fork is a characteristic feature of trees. It can be studied according to various scientific disciplines: physiology (functions of forks), architecture (dynamics of installation), anatomy (analysis of wood), biomechanics (wind-induced os-

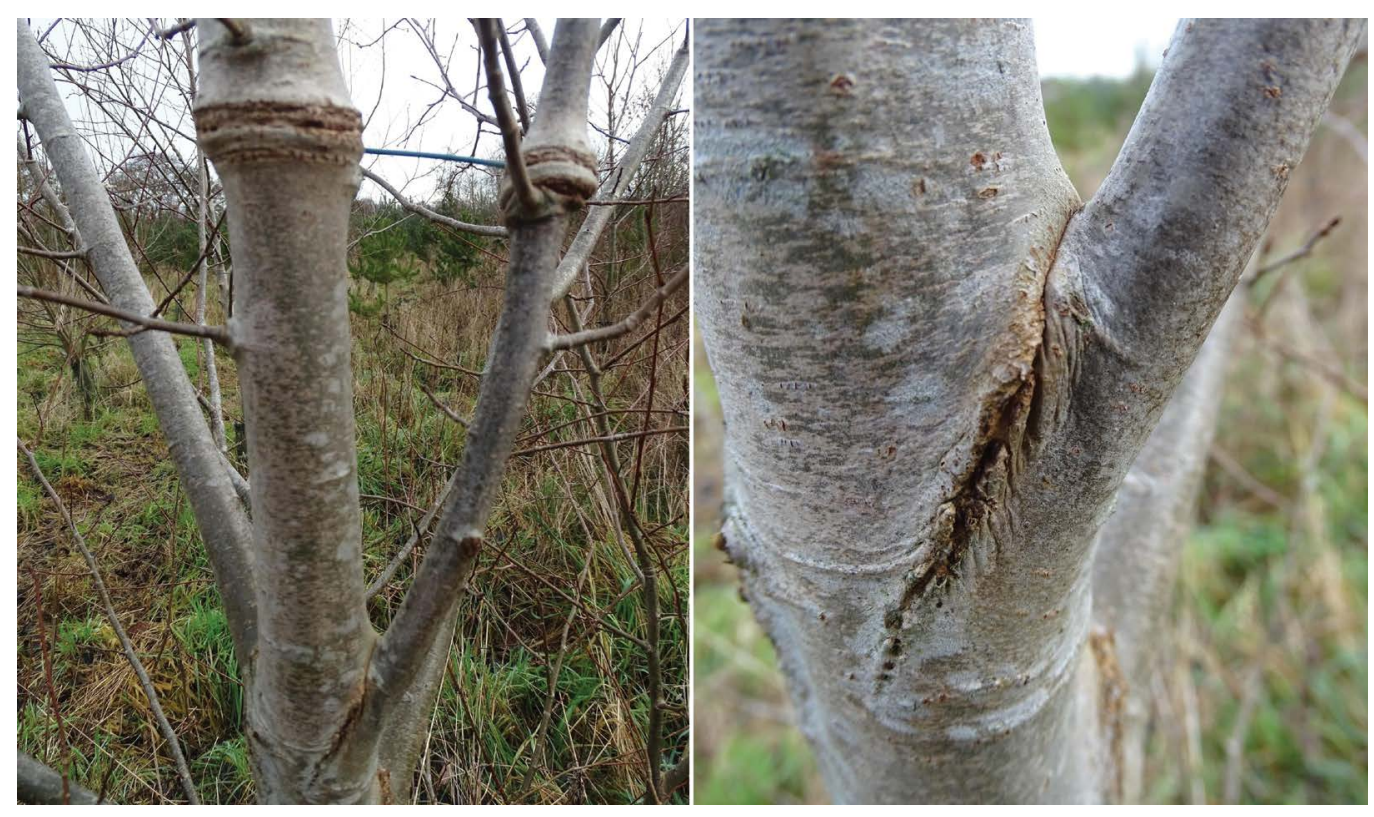

Figure 10: Induced bark inclusion in young aspen using an artificial brace (horticultural wire). 

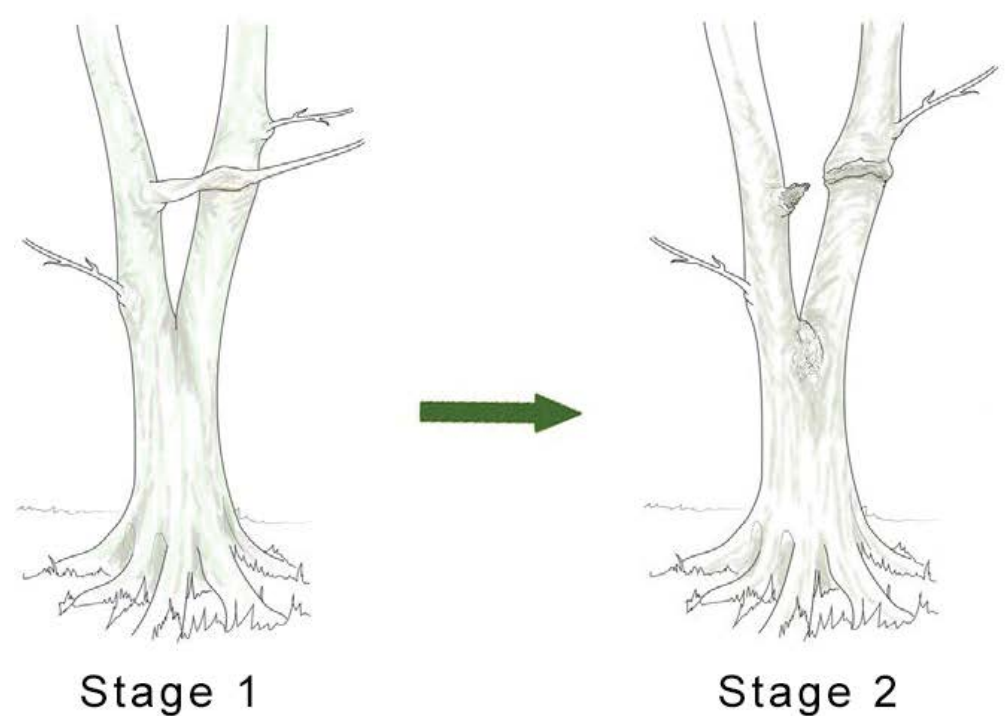

Stage 2

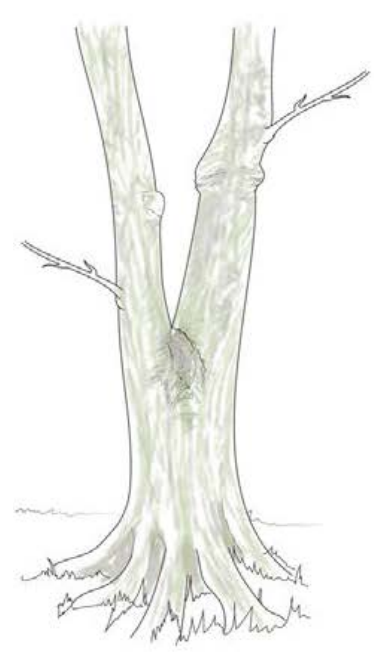

Stage 3
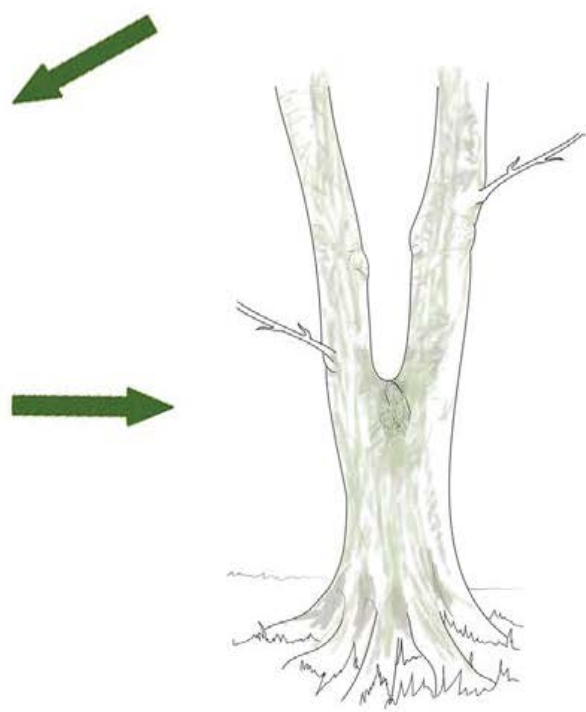

Stage 4

Figure 11: Bark-included fork resilience, after the loss of a natural brace. Stage 1: Naturally braced; Stage 2: Natural brace lost; Stage 3: Junction repair; Stage 4: Strength, solidity and stability. Repair complete.

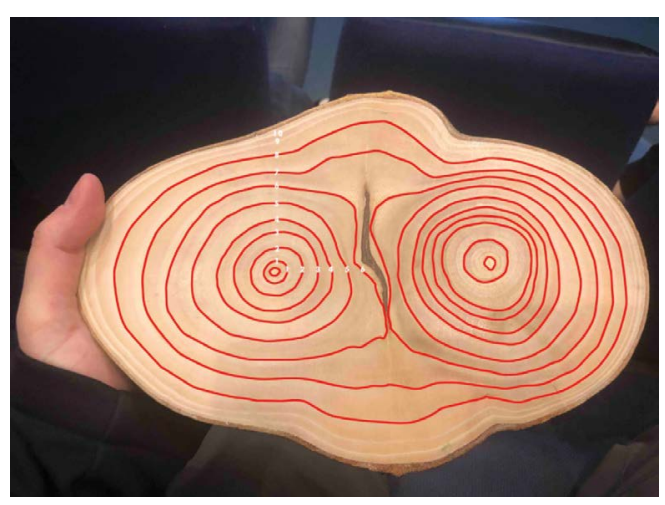

Figure 12: Cross-section providing useful evidence that where bark-meets-bark within bark-included forks (in this case, in Fraxinus excelsior), cambial activity ceases in that zone, the two cambia fuse and secondary growth begins to occlude the included bark. cillations, dynamic and static mechanical loading) and ecology (effects of resources, trauma). Although the present classification is limited to forks emerging on the trunk, the side branches and main structural branches in the crown of a tree often also form forks. The following six representations provide a synthesis of the most common types of forks previously reviewed. However, the existence of atypical forks cannot be excluded. For instance, a simple adaptive vigorous substitute shoot or even a temporary loss of apical dominance can induce a fork and lead to polyarchy (Figure 13, Figure 14, Figure 15, Figure 16, Figure 17 and Figure 18).

\section{Practical Fork Management}

These new findings on tree forks force us to review our current practices in terms of tree pruning, risk assessment, cabling and bracing (Table 2). Regarding formative pruning, we should not rush to intervene to get rid of forks compul- 

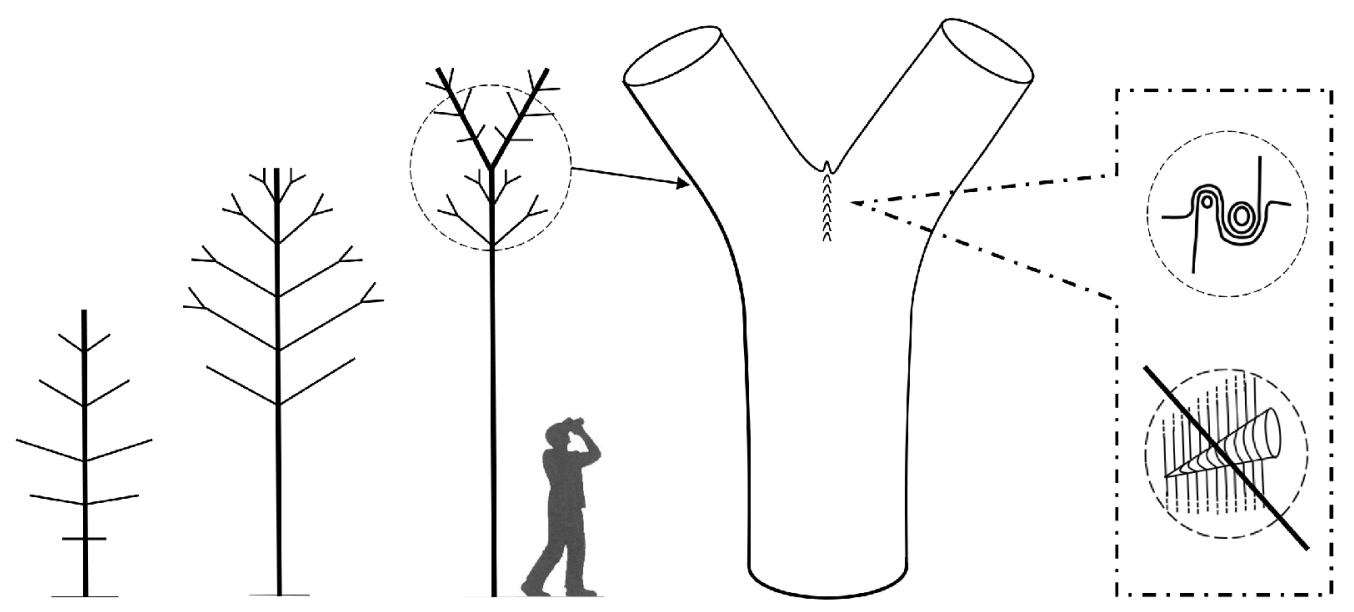

Figure 13: A main fork is the result of total reiteration of the architectural unit (far left) during the young stage. The first main fork marks the end of the trunk's construction and is preceded by lateral forks emerging on the uppermost side branches. The following main forks (not shown) are at the core of the construction of the whole crown. The elements of a main fork do not exhibit an insertion cone in the trunk but are linked together with strong and solid axillary wood under the bark ridge (insets on the right).

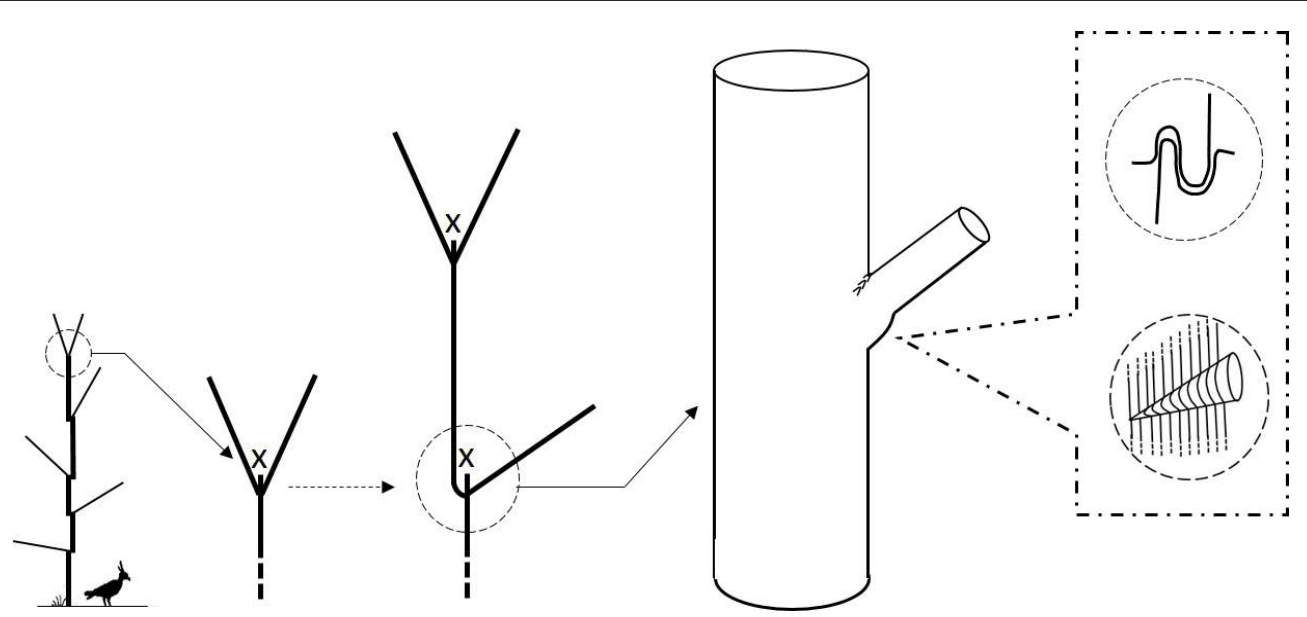

Figure 14: Recurrent forks are the result of specific modes of development in some species (superposed drooped modules, Figure 7, or, as shown here, rhythmic abortion of the terminal bud with weak apical dominance). Recurrent forks are most often resorbed within two to three years, one fork element relays the construction of the trunk (details in the figure), while the other(s) becomes a branch exhibiting an insertion cone and axillary wood (insets on the right).

sively. It may be a recurrent fork depending on the species or a main fork. Recurrent forks are better off left alone. Interfering with this mode of development causes a disruption of functioning which the tree will seek to re-establish. Although these forks are naturally resorbed over time, exogenous factors can influence a recurrent fork to persist and become perennial. For this latter case, or in the case of a main fork, if the height that the fork has established is enough for our aim, there is often no need to intervene.

Even though a standby fork is associated with a lack of light resources, a strong crisis due to transplanting can induce a standby fork even in bright light. Any pruning intervention on this 'standby', pending situation, is likely to be detrimental to the tree.

Accidental forks are not necessarily inferior to other forks, although they may have a higher probability of generating included bark due to the verticality of the arising axes and the sharply acute angle of the fork. In this case, the arising axes are considerably close to each other, making this growth form highly susceptible to developing natural braces. Thus, compromising adequate thigmomorphogenesis that generates the strengthening axillary wood at the fork.

Main forks, recurrent forks or standby forks, on the other hand, have fewer possibilities of generating included bark, since both axes arising from a fork explore, independently, the lateral vertical to oblique space generally without conflicting nor competing. In this case, the arising axes share the apical dominance instead of disputing it, and the possibility of forming natural braces is significantly lower, since both arising axes are considerably further apart, in contrast to those formed at accidental forks.

If a bark-included fork loses its natural brace, which may occur for a variety of reasons (e.g. artificial pruning, natural pruning, mortality, accidental rupture, etc.), a risk assess- 


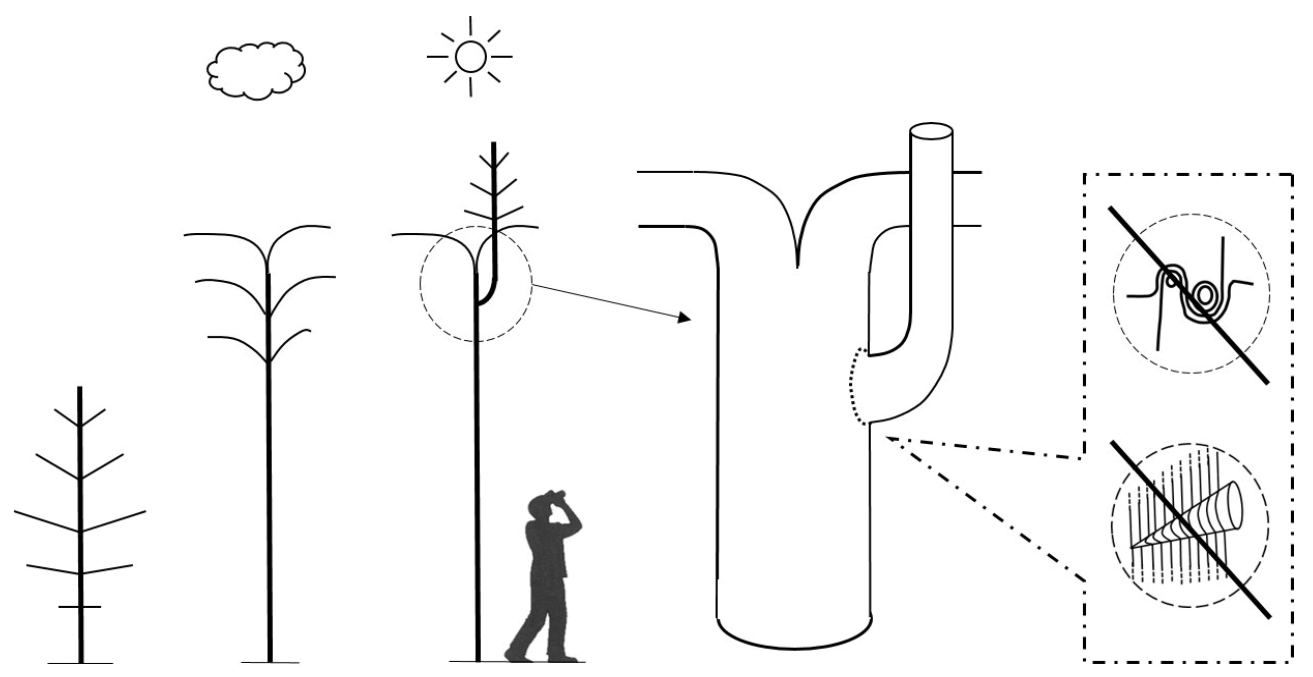

Figure 15: When growing conditions are unfavorable, especially when light is insufficient, the trunk droops and forms a fork with a side branch in order to increase the photosynthetic area. It's a 'standby' attitude resulting in a standby fork. When light resources improve, standby forks are often resorbed, usually via the emergence of an epicormic shoot (see details in the figure). The latter, unlike a branch, is initially weakly attached to the trunk without an insertion cone nor axillary wood (insets on the right). With the eventual increase of secondary growth and adequate formation of axillary wood, the junction of an epicormic shoot may become as strong in bending as that of a regular branch. According to the light context, especially in forest where the competition/thinning alternations are prevalent, a young tree can form several standby forks during its development.
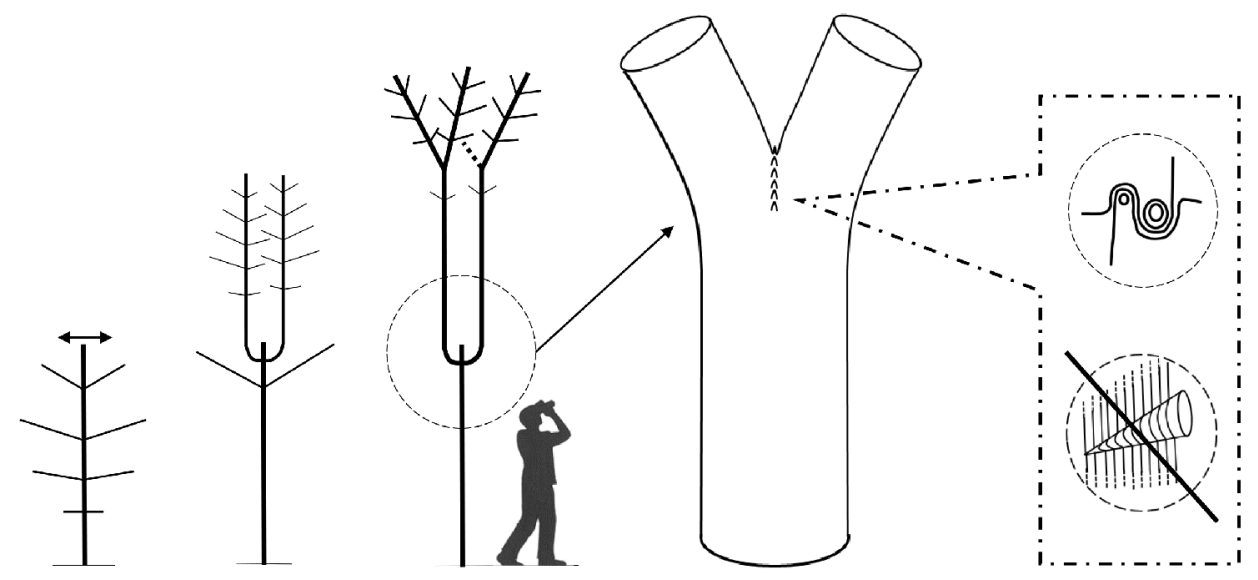

Figure 16: An accidental fork is the result of a trauma that occurred on the tip of the young trunk (double-headed arrow on far left). The elements of these forks are usually considerably close to each other due to their acute verticality and their sharp-angled insertion (each one 'tries' to relay the leader). Without natural braces, an accidental fork is as strong, solid and stable as a main fork (no insertion cones but strong and solid axillary wood. See insets on far right).

Table 2: Practical fork management recommendations.

\begin{tabular}{|l|l|}
\hline Trunk Fork Type & Pruning \\
\hline Main Fork & Formative pruning appropriate if the aim is to obtain a higher trunk \\
\hline Recurrent Fork & $\begin{array}{l}\text { Removal of a fork element inappropriate. Let the tree 'decide' which shoot will } \\
\text { relay the trunk. Intervene only if the recurrent fork seems to persist beyond } \\
\text { three years of existence below the desired trunk height }\end{array}$ \\
\hline Standby Fork & Pruning detrimental (lack of resources) \\
\hline Accidental Fork without natural braces & Formative pruning appropriate if the aim is to obtain a higher trunk \\
\hline Accidental Fork with natural braces & $\begin{array}{l}\text { Removal of a fork element may be appropriate in early stages of development. If } \\
\text { the fork is old, do not remove natural braces by default, as this may induce failure }\end{array}$ \\
\hline Accidental Fork subsequent to loss of natural braces & Risk assessment necessary \\
\hline
\end{tabular}



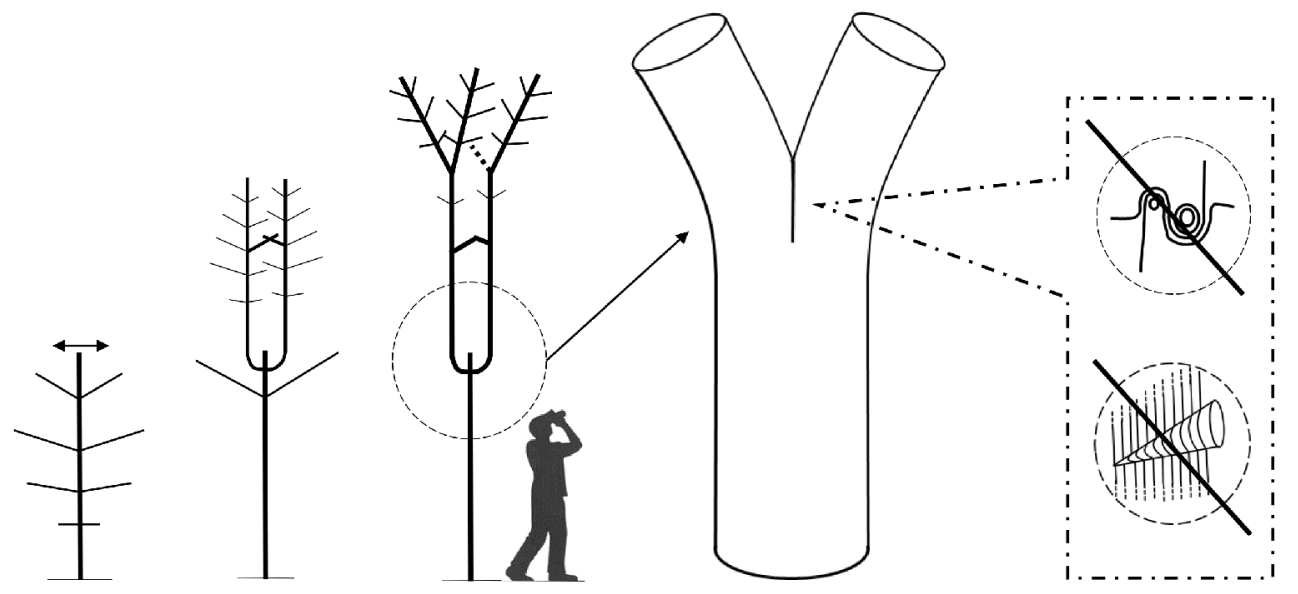

Figure 17: The probability of developing included bark is high in accidental forks with natural braces (see the crossing branches above the fork on the figure). In these cases, the weakness of the fork (no axillary wood, no insertion cone as shown by the insets) can sometimes be compensated by the strength of the natural braces.

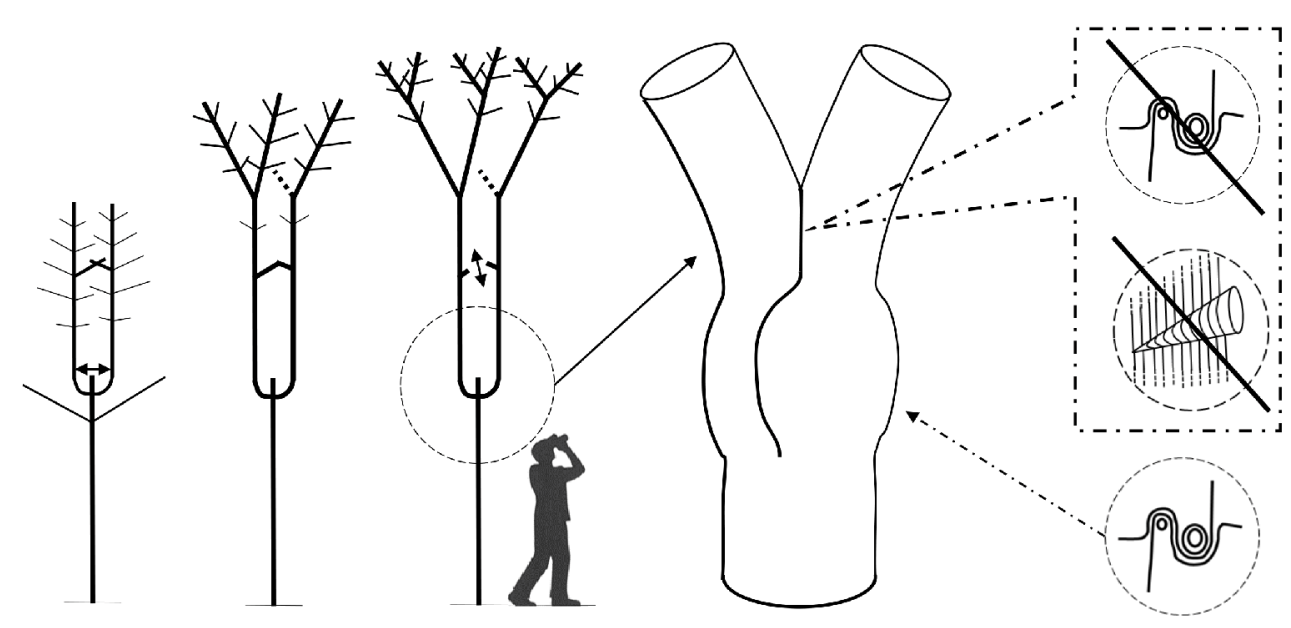

Figure 18: In the case of the loss of natural braces (vertical arrow between two branches above the encircled fork on the figure), an accidental fork with included bark is initially particularly weak. With time, this type of fork, if it does not fail before, strengthens its junction over time through a thigmomorphogenetic process and forms a reinforcing bulge, also referred to as 'big ears', the bulge consisting of strong axillary wood (inset at the bottom right).

ment should identify this weakened structure and determine a suitable course of action. For this purpose, a series of questions must be considered: How long has natural bracing been absent? Has there been recent axillary wood formation? Do we need to compensate for the missing natural brace by installing dynamic braces?

We may intervene by pruning or removing branches above a junction, predisposed to forming natural braces, and monitor future development with periodic inspections. This will ensure that the arising axes will not be restrained in order to continue 'exercising' and thus stimulate the growth of axillary wood at the fork. Also, if there are already bark-included junctions established in the main structure, we can certainly intervene in the tree while it is still young and manage them, anticipating future complications. However, when pruning adult and mature trees that have already developed a significant fork with included bark, if we are in the presence of natural braces above the fork, it may be disastrous to intervene by removing them. This action would make a weakened fork vulnerable to failure without having the strength to cope with typical wind loads.

One of the first 'rules' that tree-climbing arborists learn in pruning is to remove crossing and rubbing branches (structures which often act as natural braces). In formative pruning this may reduce the possibility of a tree developing bark-included junctions; however, in adult and mature trees, this habit may render junctions increasingly prone to failure if there is included bark in the junction below the natural brace that was removed. It would be pertinent to perform regular inspections in trees in order to spot early formation of natural braces and also to intervene proactively in axes too close to each other, in order to grow trees that are less prone to developing natural braces and therefore with a lower probability of developing bark-included junctions.

Regarding the practice of tree bracing and cabling, if we consider the proven influence of natural braces in forming 
bark-included junctions, the placing of static braces in order to 'consolidate' axes has a similar effect to natural bracing. This can considerably compromise the ability of the tree to dampen oscillations and dissipate wind energy, which is a much-needed mechanical stimulus in order to trigger an adequate thigmomorphogenetic response to reinforce junctions with the forming of axillary wood. It is considered better to place dynamic braces loosely in trees that need such safeguards.

Parallel to natural braces, when adjacent stems face dominant winds, they may form a natural windbreak barrier for other stems, impeding junctions from adequate wind-induced 'exercise', like the effect of natural bracing. Particular attention should be paid to the removal of such natural windbreaks, which may alter wind exposure and cause the exertion of unusual forces on 'unexercised' junctions. A sudden change in the tree's level of exposure to the wind will also increase (at least temporarily) the likelihood of it failing at other forks, branches, its trunk or at its roots. Even though trees may succumb to unusual wind forces coming from unpredictable directions during a storm, regular steady dominant winds make them strong, solid and stable [51-54], reinforcing their root collar and junctions through thigmomorphogenesis. If we refer to Knight's research [36], which marks a starting point of reference to the current anatomical and biomechanical approach to tree forks previously described, transplanted young trees that are staked too high experience similar effects as trees with natural bracing. The lower the tree is staked, the better the stem can sway. It is better not to stake and secure the tree with a stiff support system but to allow natural trunk movement as much as is possible. Similarly, if one wants a strong fork to develop, it needs to experience unfettered loading on a regular basis.

\section{References}

1. Matheny NP, Clark JR (1994) A photographic guide to the evaluation of hazard trees in urban areas. International Society of Arboriculture, Urbana, USA.

2. Kraft G (1884) Beiträge zur lehre von den durchforstungen, schlagstellungen und lichtungshieben. Klindworth.

3. Assmann E (1970) The principles of forest yield study. Pergamon Press.

4. Brown CL (1971) Growth and Form, Ch. III. In: Zimmerman $\mathrm{MH}_{\text {, }}$ Brown CL, Trees: Structure and function. Springer-Verlag, New York, USA.

5. Kozlowski TT (1964) Shoot growth in woody plants. The Botanical Review 30: 335-392.

6. Kozlowski TT (1971) Growth and development of trees; Vol 1. Seed Germination, Ontogeny and Shoot Growth.

7. Brown CL, McAlpine RG, Kormanik PP (1967) Apical dominance and form in woody plants: A reappraisal. American Journal of Botany 54: 153-162.

8. Zimmerman MH, Brown CL (1971) Trees: Structure and function. Springer-Verlag, New York, USA.

9. Slater D, Bradley RS, Withers PJ, et al. (2014) The anatomy and grain pattern in forks of hazel (Corylus avellana L.) and other tree species. Trees 28: 1437-1448.
10. Lilly SJ (2010) Arborists' certification study guide. International Society of Arboriculture, Champaign, IL.

11. Shigo AL (1985) How tree branches are attached to trunks. Canadian Journal of Botany 63: 1391-1401.

12. Priestley JH, LI Scott (1936) A note upon summer wood production in the tree. Proc Leeds Phil Lit Soc 3: 235-248.

13. Neely D (1991) Water transport at stem-branch junctures in woody angiosperms. J Arboric 17: 285-290.

14. Slater D, Harbinson C (2010) Towards a new model of branch attachment. Arboricultural Journal 33: 95-105.

15. Slater D (2015) The anatomy and biomechanical properties of bifurcations in Hazel (Corylus avellana L.) (Doctoral thesis, The University of Manchester, United Kingdom).

16. Nicolini E, Y Caraglio (1994) L'influence de divers caractères architecturaux sur l'apparition de la fourche chez le hêtre, en fonction de l'absence ou de la présence d'un couvert,. In: J Bouchon, Architecture des arbres fruitiers et forestiers, les colloques INRA, No. 74, 273-287.

17. Drénou C (1996) Les fourches: Un problème de taille. Forêt Entreprise 108: 43-47.

18. Nicolini E (1997) Approche morphologique du développement du hêtre (Fagus sylvatica L.). Thèse de doctorat, Université de Montpellier II, Montpellier.

19. Goethe JW von (1790) The metamorphosis of plants. MIT Press.

20. Hallé F, Ng FSP (1981) Crown construction in mature Dipterocarp trees. Malaysian Forester 44: 222-233.

21. Édelin C (1984) L'architecture monopodiale. L'exemple de quelques arbres d'Asie tropicale. Thèse, Université des Sciences et Techniques du Languedoc, Montpellier.

22. Barthélémy D, S Sabatier, O Pascal (1995) Le développement architectural du noyer commun. Forêt Entreprise 103: 61-68.

23. Nicolini E, Chanson B, Bonne F (2001) Stem growth and epicormic branch formation in understorey beech trees (Fagus sylvatica L.). Annals of botany 87: 737-750.

24. Drénou C, Caraglio Y (2019) Parlez-vous Archi: les principales définitions de la méthode Archi. Forêt Entreprise 246: 28-35.

25. Édelin C (1977) Images de l'architecture des conifères. Thèse de Doctorat, Université des Sciences et Techniques du Languedoc, Montpellier.

26. Barthélémy D, Édelin C, Hallé F (1989) Architectural concepts for tropical trees. In: LB Holm- Nielsen, IC Nielsen et H Balslev, Tropical forests. Botanical dynamics, speciation and diversity. Academic Press, London.

27. Sabatier S, D Barthélémy (1995) Architecture du cèdre de l'Atlas. In: J Bouchon, Architecture des arbres fruitiers et forestiers, les colloques INRA, No 74, 157-173

28. Loup C (1990) Le développement architectural du pin maritime. In: CR Sém. ASMA, Montpellier, février, 35-54.

29. Drénou C (1994) Approche architecturale de la sénescence des arbres. Le cas de quelques angiospermes tempérées et boréales. Thèse, Université de Montpellier II, Montpellier.

30. Bastien C, JC Bastien, E Bujon (1995) Recherche de prédicteurs précoces de la fourchaison chez le Douglas. In: J Bouchon, Architecture des arbres fruitiers et forestiers, les colloques INRA, No 74, 297-303. 
31. Armand G (1995) Feuillus précieux. IDF, Paris, France, 112.

32. Duflot H (1995) Le frêne en liberté. IDF, Paris, France. 192.

33. Slater D (2018a) Natural bracing in trees: Management recommendations. Arboricultural Journal 40: 106-133.

34. Jaffe MJ (1973) Thigmomorphogenesis: The response of plant growth and development to mechanical stimulation. Planta 114: 143-157.

35. Moulia B (2013) Plant biomechanics and mechanobiology are convergent paths to flourishing interdisciplinary research. Journal of experimental botany 64: 4617-4633.

36. Knight TA (1803) XI. Account of some experiments on the descent of the sap in trees. In a letter from Thomas Andrew Knight, Esq. to the Right Hon. Sir Joseph Banks, Bart. KBPR S. Philosophical Transactions of the Royal Society of London 277-289.

37. Telewski FW (2012) Is windswept tree growth negative thigmotropism? Plant science 184: 20-28.

38. Metzger K (1893) Der Wind als maßgeblicher Faktor für das Wachstum der Bäume. Mind Forst Heft 3: 35-86.

39. Mattheck C, Breloer H (1994b) The body language of trees: A handbook for failure analysis. HMSO Publications Centre.

40. Mattheck C (1997) Wood - the internal optimization of trees. Springer, Berlin Heidelberg, New York.

41. Mattheck C (1998) Design in nature - learning from trees. Springer, Berlin Heidelberg, New York.

42. Niklas KJ, Spatz HC (2000) Wind-induced stresses in cherry trees: Evidence against the hypothesis of constant stress levels. Trees 14: 230-237.

43. Slater D (2016a) An argument against the axiom of uniform stress being applicable to trees. Arboricultural Journal 38: 143-164.
44. Jaffe MJ, Forbes S (1993) Thigmomorphogenesis: The effect of mechanical perturbation on plants. Plant Growth Regulation 12: 313-324.

45. Fournier M, Bonnesoeur V, Deleuze C, et al. (2015) Pas de vent, pas de bois. L'apport de la biomécanique des arbres pour comprendre la croissance puis la vulnérabilité aux vents forts des peuplements forestiers. Revue Forestière Française.

46. Slater D (2018b) The association between natural braces and the development of bark-included junctions in trees. Arboricultural Journal 40: 16-38.

47. Slater D (2016b) Assessment of tree forks: Assessment of junctions for risk management. Arboricultural Association.

48. Mattheck C, Breloer H (1994a) Field guide for visual tree assessment (VTA). Arboricultural Journal 18: 1-23.

49. Mattheck C, Vorberg U (1991) The biomechanics of tree fork design. Botanica acta 104: 399-404.

50. Mattheck C (1991) Trees: The mechanical design. Springer Science \& Business Media.

51. Drénou C (2019) Face aux arbres: Apprendre à les observer pour les comprendre. Les Éditions Ulmer, Paris.

52. Kramer EM, Borkowski MH (2004) Wood grain patterns at branch junctions: modeling and implications. Trees 18: 493-500.

53. Hallé F, Oldeman RAA (1970) Essai sur l'architecture et la dynamique de croissance des arbres tropicaux. Masson et Cie, Paris.

54. Hallé F, Oldeman RAA (1975) An essay on the architecture and dynamics of growth of tropical trees. Kuala Lumpur: Penerbit Universiti Malaya.

DOI: $10.36959 / 771 / 566$

Copyright: (C) 2020 Drénou C, et al. This is an open-access article distributed under the terms of the Creative Commons Attribution License, which permits unrestricted use, distribution, and reproduction in any medium, provided the original author and source are credited. 